\title{
INFLUÊNCIA DA MONENSINA SÓDICA, PROBIÓTICO (Saccharomyces cerevisae) E COMPLEMENTO MINERAL ORGÂNICO (CROMO) NA DIETA DE NOVILHOS CONFINADOS
}

\section{The Influence of Monensin, Probiotic (Saccharomyces cerevisae) and Organic Mineral Complement (Chrome) on the Feedlot Steers Diet}

\author{
JUSTUS NETO, $\mathrm{C}^{1}$; ROSSI JUNIOR, P. $^{2}$ \\ ${ }^{1}$ Programa de Pós-graduação em Ciências Veterinárias da UFPR \\ ${ }^{2}$ Departamento de Zootecnia - UFPR \\ Endereço para correspondência: Paulo Rossi Junior - parossi@ufpr.br
}

\section{RESUMO}

Comparou-se o efeito da monensina sódica, do probiótico (Saccharomyces cerevisae) e do complemento mineral orgânico (Cromo), adicionados separadamente a uma ração a base de resíduos de pré-limpeza de milho e soja, mais uréia, calcário calcítico e silagem de milho, na alimentação de 32 novilhos em confinamento. O peso médio inicial foi de 299 $\mathrm{kg}( \pm 61 \mathrm{~kg})$ e o confinamento durou 100 dias sendo 16 dias de adaptação e três períodos de 28 dias. As pesagens foram obtidas após um jejum prévio de 16 horas. 0 delineamento experimental foi 0 de blocos ao acaso com quatro tratamentos e oito repetições. Observou-se que não houve diferença significativa $(P>0,05)$ no ganho médio diário e na conversão alimentar. Para o consumo de matéria seca foi observada diferença significativa $(P<0,05)$ entre a monensina sódica e o complemento mineral orgânico. Concluiu-se que a adição de monensina sódica, probiótico e complemento mineral orgânico não alteraram o desempenho de novilhos nas presentes condições.

Palavras-chave: aditivo, conversão alimentar, ganho de peso, ionóforo, milho.

\section{ABSTRACT}

It was compared the effect of sodic monensin, Direct-Fed Microbials (Saccharomyces cerevisae) and chrome organic mineral complement added separately to a ration made of residues of a maize and soybean first cleaning, plus urea and limestone and silage of maize, on the feeding of 32 growing steers in feed lot. The initial average weight was 299 $\mathrm{kg}(\square 61 \mathrm{~kg})$ and the feedlot lasted for 100 days, being 16-day-adaptation period (was applied) and the remaining 84 days were divided in three periods of 28 days. The steers were weighed after a previous fasting of 16 hours. The experiment was analyzed as randomized blocks design with four treatments and eight animals per treatment. It was observed no significant difference $(P>0.05)$ among the groups concerning the average daily gain and feed conversion. For the dry matter intake it was observed significant difference $(P<0.05)$ between the sodic monensin and the chrome organic mineral complement. It was concluded that the adding of sodic monensin, DFM and the chrome organic mineral complement did not alter the performance of the steers under the present conditions.

Key words: additives, average daily gain, feed:gain ratio, ionophore. maize. 


\section{INTRODUÇÃO}

Os resíduos agro-industriais são fontes alternativas de alimentos que podem ser amplamente utilizados em dietas de bovinos. Para obter o máximo aproveitamento destes, a utilização de aditivos nas dietas faz-se necessária, pois na maioria das vezes a qualidade dos resíduos é baixa.

Os ionóforos atuam sobre a população microbiana do rúmen, na membrana celular dos microorganismos. Por se tornarem solúveis em membranas após serem combinados com íons, os ionóforos passam a fazer parte destas e desempenhar as funções de transporte de íons, nas bactérias gram-positivas, de um lado a outro da membrana (MACHADO e MADEIRA, 1990).

Esta função de transporte pela membrana promove seleção das bactérias, em que as gram-positivas são reduzidas em número, promovendo conseqüentemente mudança no padrão de fermentação ruminal. Estas mudanças no padrão de fermentação ruminal ocorrem porque as bactérias gram-positivas são as principais produtoras de acetato, butirato e gás hidrogênio enquanto que as gramnegativas produzem como produto final da fermentação o succinato, precursor do propionato. Tais alterações energéticas são desejáveis, uma vez que a maior retenção de carbono aumenta o desempenho animal, observando-se aumentos de até $20 \%$ de energia metabolizável disponível para o animal em dietas com adição de monensina (SILVA, 1990). Como os ionóforos, os probióticos (Saccharomyces cerevisae) atuam sobre a população microbiana, o que gera mudanças na fermentação ruminal e, conseqüentemente, influi sobre o desempenho do animal.

No rúmen, os efeitos observados pelo probiótico são de maneira geral: o aumento do número de bactérias celulolíticas, o que melhora a digestão da fração fibrosa; a produção de fatores de crescimento para os microrganismos do rúmen; o aumento do número de bactérias Selenomonas ruminantium; o aumento da produção de propionato, acetato, succinato e do total de ácidos graxos voláteis no rúmen (MARTIN e NISBET, 1992).

Os novos avanços no campo da nutrição animal, em especial na área dos complexos de minerais orgânicos, têm permitido uma maior resposta em produtividade na exploração zootécnica de ruminantes.

Atualmente, a influência da suplementação do cromo orgânico na resposta imunológica e nos casos de estresse, seja por desmama, transporte, castração ou outros tipos de situações estressantes, está sendo tema de muitas pesquisas em função da constatação de que o cromo causa diminuição da concentração sérica de cortisol (BARUSELLI, 2000).

Outros estudos demonstraram que a suplementação com cromo aumentou a massa muscular e reduziu a gordura corporal. Tais estudos sugeriram que ruminantes em fase de acabamento (fase final de engorda) não deveriam receber suplementação mineral contendo cromo para não prejudicar a necessária cobertura de gordura da carcaça (BARUSELLI, 2000).

O presente trabalho teve como objetivo estudar a influência da monensina sódica (ionóforo), Saccharomyces cerevisae (probiótico) e do Cromo em complexo mineral orgânico adicionados a uma ração a base de resíduos de prélimpeza de milho e soja na recria de novilhos em regime de confinamento.

\section{MATERIAL E MÉTODOS}

O experimento teve duração de 100 dias, dos quais houve um período de adaptação de 16 dias, seguido de três períodos de 28 dias para coleta de dados. Foram utilizados 32 novilhos $7 / 8$ da raça Charolesa com idade média ao início do 
experimento de 9 meses e peso médio de $299 \mathrm{~kg}( \pm 61 \mathrm{~kg})$. Os animais foram alojados em 8 boxes em regime de confinamento fechado, com disponibilidade de 2,3 $\mathrm{m}^{2}$ de cocho e uma área de 4,47 $\mathrm{m}^{2}$ por animal, em piso ripado de concreto e bebedouro regulado por bóia automática.

O delineamento experimental utilizado foi o de blocos ao acaso, em que para a distribuição dos tratamentos e das repetições os animais foram selecionados em ordem crescente de peso, sendo que a cada 4 animais se formava um lote e os tratamentos foram distribuídos em dois blocos, sendo um bloco com um lote leve e outro com um lote pesado escolhidos ao acaso. Os lotes foram pesados a cada 28 dias, com um jejum total prévio de 16 horas.

A dieta base dos tratamentos era constituída de concentrado $(72 \%$ resíduo de soja $+25 \%$ resíduo de milho $+2 \%$ uréia $+1 \%$ calcário calcítico) + suplemento mineral e como volumoso a silagem de milho. Na Tabela 1 são apresentadas as composições dos resíduos de soja, milho e da ração a qual foram acrescentados os aditivos em estudo.

Os animais foram alimentados duas vezes ao dia, sendo o concentrado na proporção de $66 \%$ no período da manhã e $34 \%$ no período da tarde, e o volumoso na proporção de $50 \%$ no período da manhã e $50 \%$ no período da tarde. Antes de cada refeição as sobras eram coletadas e pesadas para controle do consumo por bloco.

Para o cálculo inicial do consumo utilizou-se a tabela do NRC (1996) para novilhos de 250 - $300 \mathrm{~kg}$ de peso vivo, em que ficou estabelecido o consumo de $3 \mathrm{~kg}$ de concentrado e $15 \mathrm{~kg}$ de volumoso com base na análise dos ingredientes. A quantidade de volumoso fornecida inicialmente foi ajustada no decorrer do experimento, acrescentando ou reduzindo, de acordo com 0 consumo diário respeitando a relação volumoso/ concentrado de 66:34 na matéria seca.
Os aditivos foram pré-misturados manualmente ao concentrado no momento de cada refeição. As especificações e dosagens encontram-se na Tabela 2.

Os dados de ganho médio diário, conversão alimentar e consumo de matéria seca nos três períodos foram analisados pelo teste de médias (Tukey 0,5\%) utilizando o sistema Statistica 6.0.

\section{RESULTADOS E DISCUSSÃO}

O peso vivo inicial e final dos animais, nos tratamentos são apresentados na Tabela 3.

A influência do período sobre o GMD nos tratamentos encontra-se na Tabela 4. Dentro do Tratamento 01 (probiótico) o GMD no terceiro período foi significativamente superior ao no primeiro período $(P<0,05)$ demonstrando que em novilhos em crescimento o efeito do tempo de confinamento ocorreu havendo maior ganho de peso na fase final, a partir dos 56 dias. MEDRONI et al. (1998) em um experimento semelhante constataram um GMD superior $(P<0,05)$ no primeiro período com relação aos demais, diferente do resultado obtido neste trabalho.

No Tratamento 02 (monensina sódica), o GMD no terceiro período foi superior $(P<0,05)$ ao no segundo período demonstrando melhor desempenho dos animais que receberam ionóforo a partir dos 56 dias de confinamento. PRADO et al. (1995) em experimento semelhante com novilhas não encontraram diferença significativa $(P>0,05)$ do GMD entre os períodos. MAGLIOCCA et al. (1994) obtiveram resultados para a monensina com ganho de peso superior a partir dos 28 dias de confinamento $(P<0,01)$ até os 56 dias.

No Tratamento 03 (testemunha), 0 GMD no segundo período foi superior $(\mathrm{P}<$ $0,05)$ ao no terceiro período, demonstrando um melhor desempenho dos animais alimentados com a ração base isolada até os 56 dias de confinamento. 
Tabela 1 - Composição dos resíduos de soja, milho e da ração concentrada.

\begin{tabular}{lccc}
\hline COMPOSIÇÃO & Resíduo de soja & Resíduo de milho & Ração \\
\hline Matéria Seca (\%) & 88,51 & 90,25 & 87,14 \\
Proteína bruta (\%) & 10,05 & 9,5 & 16,24 \\
Extrato etéreo (\%) & 3,05 & 3,88 & 3,38 \\
Fibra bruta (\%) & 37,65 & 3,17 & 7,54 \\
Cálcio & 0,60 & 0,11 & 0,93 \\
Fósforo & 0,13 & 0,34 & 0,97 \\
\hline
\end{tabular}

Tabela 2 - Tratamentos utilizados: especificações e dosagens.

\begin{tabular}{ccc}
\hline Tratamentos & Especificações & Dosagens (g/cab/dia) \\
\hline PROBIÓTICO & Leveduras inativas e ativas & 10 \\
MONENSINA & Monensina sódica & 0,2 \\
TESTEMUNHA & & Ração Base \\
CROMO & Complemento mineral orgânico - Cromo & 100 \\
\hline
\end{tabular}

Tabela 3 - Peso vivo inicial e peso vivo final dos animais nos tratamentos.

\begin{tabular}{ccc}
\hline Tratamento & \multicolumn{3}{c}{ Peso Vivo $(\mathrm{kg})$} \\
\cline { 2 - 3 } & Inicial & Final \\
\hline PROBIÓTICO & 320 & 415 \\
MONENSINA & 315 & 407 \\
TESTEMUNHA & 317 & 410 \\
CROMO & 327 & 430 \\
\hline
\end{tabular}

Tabela 4 - Efeito dos tratamentos e períodos sobre o ganho médio diário de novilhos em confinamento.

\begin{tabular}{ccccc}
\hline Tratamento & \multicolumn{5}{c}{ Ganho Médio Diário $(\mathrm{kg} /$ dia $)$} \\
\cline { 2 - 5 } & $1^{\circ}$ Período & $2^{\circ}$ Período & $3^{\circ}$ Período & Média \\
\hline PROBIÓTICO & $0,853^{\mathrm{A}} \mathrm{b}$ & $1,165^{\mathrm{AB}} \mathrm{ab}$ & $1,343^{\mathrm{A}} \mathrm{a}$ & 1,120 \\
MONENSINA & $1,045^{\mathrm{A}}$ ab & $0,884^{\mathrm{B}} \mathrm{b}$ & $1,343^{\mathrm{A}} \mathrm{a}$ & 1,090 \\
TESTEMUNHA & $1,094^{\mathrm{A}}$ ab & $1,370^{\mathrm{A}} \mathrm{a}$ & $0,968^{\mathrm{A}} \mathrm{b}$ & 1,144 \\
CROMO & $0,991^{\mathrm{A}}$ & $1,406^{\mathrm{A}}$ & $1,272^{\mathrm{A}}$ ab & 1,223 \\
\hline
\end{tabular}

NOTA: Médias seguidas por letras minúsculas diferentes nas linhas e médias seguidas por letras maiúsculas diferentes nas colunas, diferem entre si pelo teste de Tukey $(P<0,05)$.

Tabela 5 - Efeito dos tratamentos e períodos sobre a conversão alimentar.

\begin{tabular}{ccccc}
\hline Tratamento & \multicolumn{4}{c}{ Conversão Alimentar $(\mathrm{kg} \mathrm{MS} / \mathrm{Kg}$ Ganho) } \\
\cline { 2 - 5 } & $1^{\circ}$ Período & $2^{\circ}$ Período & $3^{\circ}$ Período & Média \\
\hline PROBIÓTICO & 7,72 & 7,10 & 6,62 & 7,15 \\
MONENSINA & 5,80 & 7,90 & 5,37 & 6,35 \\
TESTEMUNHA & 6,02 & 6,00 & 11,00 & 7,98 \\
CROMO & 6,66 & 6,42 & 7,85 & 6,98 \\
\hline
\end{tabular}

Tabela 6 - Efeito dos tratamentos e períodos sobre o consumo de matéria seca.

\begin{tabular}{ccccc}
\hline Tratamento & \multicolumn{4}{c}{ Consumo de Matéria Seca (kg/dia) } \\
\cline { 2 - 5 } & $1^{\circ}$ Período & $2^{\circ}$ Período & $3^{\circ}$ Perí́do & Médias \\
\hline PROBIÓTICO & $6,55^{\mathrm{a}}$ & $7,99^{\mathrm{a}}$ & $8,89^{\mathrm{a}}$ & $7,81^{\mathrm{AB}}$ \\
MONENSINA & $6,03^{\mathrm{a}}$ & $6,97^{\mathrm{a}}$ & $7,25^{\mathrm{a}}$ & $6,74{ }^{\mathrm{A}}$ \\
TESTEMUNHA & $6,54^{\mathrm{a}}$ & $8,23^{\mathrm{a}}$ & $8,81^{\mathrm{a}}$ & $7,86^{\mathrm{AB}}$ \\
CROMO & $6,60^{\mathrm{b}}$ & $9,00^{\mathrm{ab}}$ & $10,0^{\mathrm{a}}$ & $8,54^{\mathrm{B}}$ \\
\hline
\end{tabular}

NOTA: Médias seguidas por letras minúsculas diferentes nas linhas e médias seguidas por letras maiúsculas diferentes nas colunas, diferem entre si pelo teste de Tukey $(P<0,05)$. 
No Tratamento 04 (cromo), o GMD do segundo período foi superior $(P<0,05)$ ao primeiro período, demonstrando melhor desempenho desses animais a partir dos 28 dias de confinamento.

Não houve influência dos tratamentos sobre o GMD no primeiro e terceiro período $(P>0,05)$, como pode ser observado na Tabela 4. No segundo período os Tratamentos 01,03 e 04 foram semelhantes e superiores ao Tratamento 02.

Não houve influência do período de 85 dias de confinamento sobre o GMD (P > $0,05)$ como pode ser observado na Tabela 4.

COSTA et al. (1987) constataram que após os 112 dias de tratamento com levedura não houve efeito significativo entre os tratamentos $(P>0,05)$. CASEY et al. (1994) analisando o ganho médio diário de 60 novilhos em confinamento obtiveram diferença significativa $(P<0,05)$ entre 0 tratamento monensina sódica e a testemunha no ganho de peso final, sendo que a monensina obteve um ganho superior. MOOSIE-SHAGGEER e MOWAT (1993) observaram que a adição de cromo na dieta promoveu uma melhoria no ganho médio diário $(P<0,05)$.

Para a conversão alimentar não houve influência $(P>0,05)$ dos tratamentos e períodos, como pode ser observado na Tabela 5.

PRADO et al. (1995) não constataram diferença significativa $(P>0,05)$ para a conversão alimentar confrontando monensina com o tratamento testemunha. SALLES e LUCCI (1998), em experimento estudando 0 desempenho de bezerros alimentados com rações aditivadas com monensina também não observaram diferença significativa $(P>0,05)$ entre os tratamentos. KEGLEY e SPEARS (1995), ao analisarem a influência do cromo sobre a conversão alimentar concluíram que não houve efeito significativo do tratamento realizado $(P>0,05)$. Estas observações vão de encontro aos resultados obtidos neste experimento.

Para o consumo de matéria seca aos 85 dias de confinamento, o Tratamento 02 apresentou o menor consumo $(P<0,05)$ em relação ao Tratamento 04 e consumo semelhante aos Tratamentos 01 e 03 como pode ser observado na Tabela 6 .

SILVA et al. (1991) constataram que a monensina adicionada na ração reduziu ( $P$ $<0,05)$ o consumo de matéria seca, por outro lado, LANNA et al. (1995) observaram uma redução de $33 \%$ no consumo de alimento em 96 dias de tratamento, em novilhas mantidas em pastagens recebendo dieta com levedura. SALLES e LUCCI (1998) observaram que animais tratados com monensina consumiram mais que os de tratamento controle.

No consumo de matéria seca 0 tratamento com cromo (T4) apresentou um consumo superior $(P<0,05)$ no terceiro período em relação ao primeiro período, como pode ser observado na Tabela 6.

Não houve diferença entre os tratamentos nos períodos 01, 02 e $03(\mathrm{P}>$ 0,05).

\section{CONCLUSÕES}

Nestas condições experimentais, o uso dos aditivos monensina sódica, probiótico e cromo na forma de complemento mineral, adicionados a dieta de novilhos confinados, em fase de recria, não influencia o ganho médio diário e a conversão alimentar, porém a monensina sódica promove menor consumo de matéria seca.

\section{REFERÊNCIAS}

BARUSELLI, M. S. Minerais Orgânicos: o que são, como funcionam e vantagens do seu uso em ruminantes. In: SIMPÓSIO INTERNACIONAL DE PATOLOGIA CLÍNICA VETERINÁRIA, II. 2000, Anais.... Botucatu - SP, FMVZ-UNESP, 2000 p. 218. 
CASEY, N.H.; WESSELS, R.H.; NEISSNER, H.H. Feedlot Agrouth performance of steers os salinuo mycin, moneusin and a daily rottion beturen the two. S. Af. Vet. Ver, v.65, n.4, p.160-163, 1994.

COSTA, T.A.F.; VIEIRA, P.F.; SAMPAIO, A.A.M.; OLIVEIRA, M.D.S. et al. In: Revista da Sociedade Brasileira de Zootecnia,v. 15 (6), p. 548-554, 1987.

KEGLEY, E. B.; SPEARS, J.W.; 1995. Immune Response, Glucose Metabolism, and Performance of streesses feeder calves fed inorganic or organic chromium. Journal of Animal Science, v.73, n.9, p.2721-2726, 1995.

LANNA, D.P.D.; BOIN, C., FOX; D.G. et al. Substituição de Farelo de Soja por Levedura para Animais em crescimento Recebendo Bagaço de Cana Hidrolisado.. In: REUNIÃO ANUAL DA SBZ, XXXII, 1995, Brasília. Anais...Brasília: Sociedade Brasileira de Zootecnia, 1995, p.197-198.

MACHADO, P. F.; MADEIRA, H.M.F. Manipulação de nutrientes em nível de rúmen efeitos do uso de ionóforos. In: NOVAS TECNOLOGIAS DE PRODUÇÃO ANIMAL, 1990, Campinas, Anais... Campinas: Sociedade Brasileira de Zootecnia 1990, p. 41-58.

MAGLIOCCA, F.C.; SILVEIRA, A.C.; FURLAN, L.R. et al. Efeito da niacina e da monensina sódica no desempenho de novilhos em confinamento. Pesquisa Agropecuária Brasileira, Brasília, v. 29(6): 979-982, 1994.

MARTIN, S.A.; NISBET, D.J. Effect of Direct-fed microbials on rúmen microbial Fermentation. Journal of Dairy Science, v. 75 (6): 1736-1744, 1992.

MEDRONI, S.; PRADO, I.N.; NASCIMENTO, W.G. et al. Efeito da combinação de dietas com milho ou triticale e farelo de soja ou levedura no desempenho de novilhas nelore confinadas. In: REUNIÃO ANUAL DA SBZ, XXX, 1998, Botucatu, SP. Anais..., Botucatu: Sociedade Brasileira de Zootecnia, 1998, p.614-616.

MOONSIE-SHAGEER, S.; MOWAT, D.N. Effect of level of supplemental chromium on performance, Serum constituents, and immune status of stressed feeder claves. Journal of Animal Science, v. 71, p. 232-238, 1993.

NATIONAL RESEARCH COUNCIL - NRC. Nutrient requirements of beef cattle. Washington, D.C.: National Academy of Sciences, 1996, 242 p.

PRADO, I.N.; EVERLING, D.M.; BRANCO, A.F. et al. Influência da Monensina Sódica ou Bicarbonato de Sódio sobre o Consumo e Desempenho de Novilhas Confinadas. In: REUNIÃO ANUAL DA SBZ, XXXII, 1995, Brasília. Anais..., Brasília: Sociedade Brasileira de Zootecnia, 1995, p.321-322.

SALLES, M.S.V.; LUCCI, C.S. Monensina para Bezerros Ruminantes em Crescimento Acelerado I. Desempenho. In: REUNIÃO ANUAL DA SBZ, XXXV, 1998. Botucatu. Anais..., Botucatu: Sociedade Brasileira de Zootecnia, 1998, p.446-448.

SILVA, S.C. Efeito de bicarbonato de sódio, e/ou lasalocida sobre os parâmetros ruminais de bovinos alimentados com bagaço de cana tratado a pressão de vapor. Piracicaba, 1990. Dissertação de Mestrado, Escola Superior de Agricultura Luiz de Queiroz, Universidade de São Paulo. $130 \mathrm{p}$.

SILVA, J.F.C.; VALADARES FILHO, S.C.; LEÃO MARIA I. Efeito da monensina sódica e da uréia sobre o consumo, parâmetros ruminais, a digestibilidade aparente e o balanço nutricional em bovinos. Revista Brasileira de Zootecnia, v. 20(5), p. 455-470, 1991. 